\title{
Breastfeeding practice in Kuwait: determinants of success and reasons for failure
}

\author{
M.F. Nassar, ${ }^{1}$ A.M. Abdel-Kader, ${ }^{2}$ F.A. Al-Refaee, ${ }^{3}$ Y.A. Mohammad, ${ }^{3}$ S. Al Dhafiri, ${ }^{4}$ S. Gabr ${ }^{4}$ and S. Al-Qattan ${ }^{4}$
}

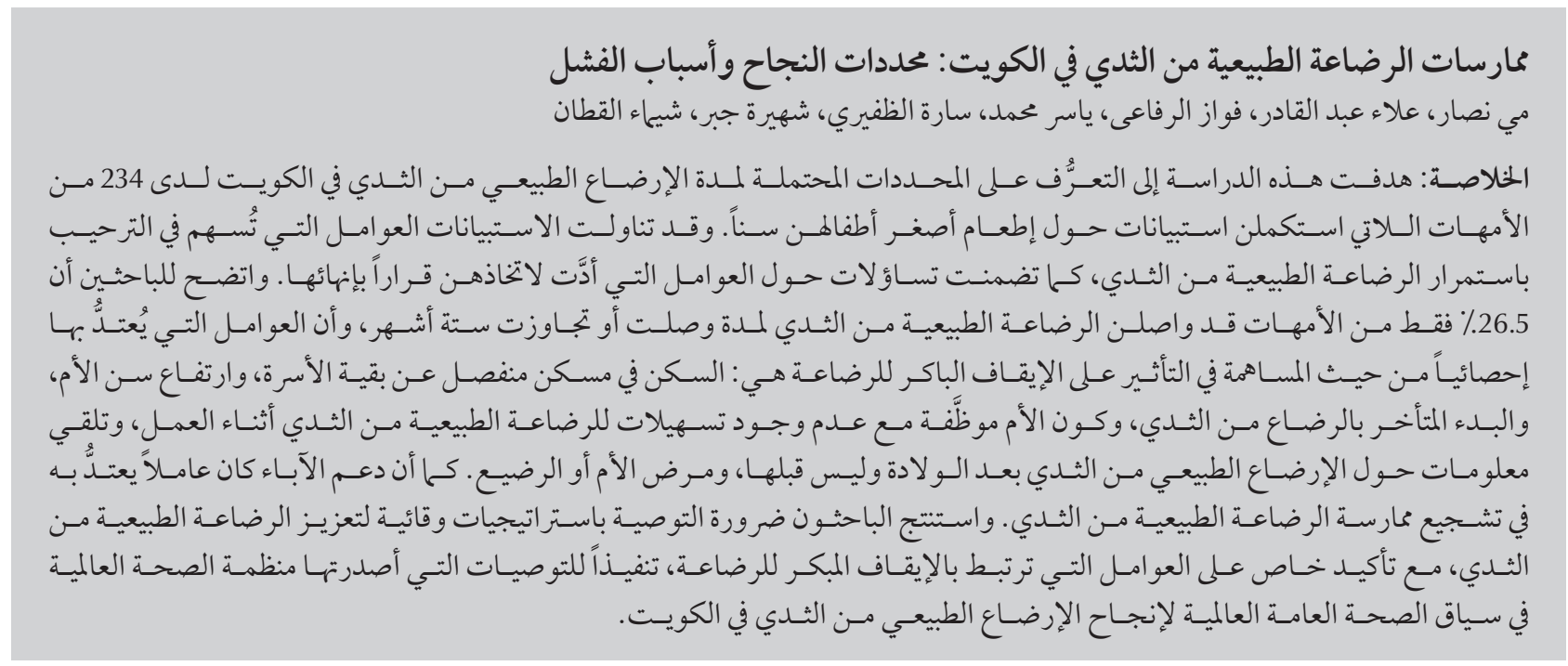

ABSTRACT To explore the possible determinants of duration of breastfeeding in Kuwait, 234 mothers completed a questionnaire concerning the feeding of their youngest infant. The questionnaire addressed the factors that contributed to their willingness to continue breastfeeding and enquired about the factors leading to their decision to end it. Only $26.5 \%$ of the mothers had continued breastfeeding for 6 months or more. Separate family housing, higher maternal age, late initiation of breastfeeding, being employed without the feasibility to breastfeed at work, breastfeeding information given after rather than before birth, and maternal and infant sickness were all significant contributors influencing early cessation. Father's support was a significant factor that encouraged the practice. In conclusion, preventive strategies are recommended for boosting breastfeeding, with special emphasis on the factors linked to early cessation, aiming at full implementation of the WHO global public health recommendations for successful breastfeeding in Kuwait.

\section{Pratique de l'allaitement maternel au Koweït : déterminants de réussite et motifs d'échec}

RÉSUMÉ Afin d'étudier les déterminants possibles de la durée de l'allaitement maternel au Koweït, 234 mères ont rempli un questionnaire sur l'alimentation de leur plus jeune enfant. Le questionnaire portait sur les facteurs contribuant à leur volonté de poursuivre l'allaitement et sur les facteurs qui les ont conduit à leur décision d'y mettre fin. Seules 26,5 \% des mères ont allaité au sein pendant au moins 6 mois. Les facteurs contribuant significativement à un arrêt précoce de l'allaitement au sein étaient les suivants : une résidence familiale séparée, un âge maternel élevé, une initiative tardive de l'allaitement, un emploi sans possibilité d'allaiter sur le lieu de travail, une communication sur l'allaitement faite après la naissance plutôt qu'avant, et une affection chez la mère et/ou chez l'enfant. Le soutien du père était un facteur important qui favorisait la pratique de l'allaitement. En conclusion, des stratégies préventives sont recommandées afin de promouvoir l'allaitement au sein tout en prenant particulièrement en compte les facteurs liés à un arrêt précoce de l'allaitement, et de viser une mise en oeuvre intégrale des recommandations mondiales de l'OMS en santé publique pour la réussite de l'allaitement maternel au Koweït.

'Department of Paediatrics, Faculty of Medicine,_Ain Shams University, Cairo, Egypt (Correspondence to M.F. Nassar: maie_nassar@yahoo.co.uk). ${ }^{2}$ Department of Paediatrics, Faculty of Medicine, University of Mansoura, Dakahlia, Egypt. ${ }^{3}$ Gastroenterology, Hepatology and Nutrition Unit, Department of Paediatrics; ${ }^{4}$ Department of Food and Nutrition, Al Adan Hospital, Ministry of Health, Kuwait.

Received: 06/11/13; accepted: 23/02/14 


\section{Introduction}

Breastfeeding is an unequalled way of providing ideal food for the healthy growth and development of infants. As a global public health recommendation, infants should be exclusively breastfed for the first 6 months of life to achieve optimal growth, development and health. To meet their evolving nutritional requirements, infants should receive nutritionally adequate and safe complementary foods while breastfeeding continues for up to 2 years of age or beyond (1).

Although developed countries debate the World Health Organization's (WHO) recommendation of 6 months' exclusive breastfeeding (1), Morales et al. advised promotion of predominant breastfeeding for 4-6 months to reduce the burden of allergic manifestations and infections in infancy (2). Earlier in 2001 Kramer et al. reported that increasing the duration and degree of breastfeeding decreased the risk of gastrointestinal tract infection and atopic eczema in the first year of life (3). Recently, Nwaru et al. stated that longer duration of total breastfeeding, rather than its exclusivity, was protective against the development of non-atopic asthma (4).

Regarding the situation in Kuwait, Dashti et al. in 2010 reported a high rate of breastfeeding initiation (92.5\% of their studied sample of mothers); however, at discharge from hospital, only $84.8 \%$ of participants were breastfeeding their infants, with less than one-third of mothers (29.8\%) fully breastfeeding and only $10.5 \%$ exclusively breastfeeding (5). Earlier, Al-Bustan and Kholi studied a sample of 1553 Kuwaiti married women during 1985 and found that the proportion of children breastfeeding at 6 months ranged from $35 \%$ to $44 \%$ (6). This discrepancy between the percentage who initiate and those who continue, as well as the fact that there are no recent data concerning the duration of breastfeeding in Kuwait, inspired the design of the current study. Considering the low percentage of exclusive breastfeeding at hospital discharge in Kuwait, as reported by Dashti et al. (5), the current study was designed to examine the possible determinants of any breastfeeding during the first 6 months of life. Targeting those factors would help develop strategies for boosting the duration of breastfeeding and hence fulfil the goals set by WHO.

\section{Methods}

\section{Study design and sample}

This exploratory study included 280 women of childbearing age living in $\mathrm{Ku}-$ wait. The study was conducted between December 2012 and June 2013 and included mothers seeking medical advice for their children in the outpatient clinics of Al Adan Hospital. Al Adan Hospital is one of the biggest general governmental hospitals in Kuwait that offer medical health services to the population of $\mathrm{Al}$ Ahmadi region located south of Kuwait. Two paediatric clinics, attended weekly by the principal researcher, were used for recruiting Arab mothers to the study.

\section{Data collection}

A questionnaire based on that of the Infant Feeding Practices Study II by the Centers for Disease Control and Prevention (7) was translated to Arabic and back translated to English for verification by independent personnel. Finally, the Arabic form was pilottested on 20 randomly chosen mothers. The questionnaire was modified for better comprehension as perceived by the mothers. After obtaining their informed verbal consent, each eligible mother completed the questionnaire concerning the feeding history of their 2-3-year-old child. The questionnaire was administered by the researchers via a face-to-face interview, which had the advantage of ensuring that it was understood and fully completed. Only Arab mothers were targeted to ensure proper understanding of the questionnaire and to nullify the effect of culture and ethnic differences on breastfeeding. Mothers who refused to participate and those giving birth to premature babies with congenital malformations or needing neonatal intensive care (NICU) admission were excluded from the study.

The questionnaire included $3 \mathrm{sec}$ tions. The first explored the sociodemographic data of the mother and details about her infant's diet history. The second addressed the factors that might have contributed to her willingness to continue breastfeeding, and the last section enquired about the factors leading to her decision to end breastfeeding. The weight of each factor was requested as a 4-point Likert scale (not important, somewhat important, important, very important).

\section{Data analysis}

SPSS statistical package, version 20, was used for data analysis. Descriptive statistics were generated for demographic factors, the chi-squared test was used to compare categorical data and the $t$-test was used to compare continuous data. For assessment of factors associated with breastfeeding cessation at 6 months of age we used multivariate Cox regression analyses. A total of 21 variables were included in the final model that was constructed using factors that had an association with breastfeeding duration based on the univariate association (the level of significance was set at $P<0.05$ ), as well as factors reported to influence breastfeeding initiation and duration from previous studies $(5,6,8-10)$ and that were considered to potentially affect breastfeeding practice in our local region.

The variables included in the multivariate Cox regression models were: mother's age (years), nationality (Kuwaiti, non-Kuwaiti), education (primary, secondary, university), residence (living within family home, separate housing), whether the mother had breastfed before (yes or no), when the 
mother started to breastfeed (hours), time of weaning (months), mothers' ability to breastfeed at work (not employed, employed and can or cannot breastfeed at work), time the mother received information regarding breastfeeding (during pregnancy, after birth), source of breastfeeding information (doctor, nurse, relatives and friends, the media), adequacy of milk production during the first week of breastfeeding as perceived by the mother (adequate, inadequate), child's birth order (1st, 2nd, 3rd, 4th, $>4$ th). The following variables were also included in the initial model, each assessed on a 4-point Likert scale (not important, somewhat important, important, very important): mother's perception of the effect of encouragement to continue breastfeeding from $\mathrm{fa}$ ther, grandmother, doctor and treating team; mother's perception of the effect of her own illnesses or her baby's illness (if any) on continuation of breastfeeding; mother's perception of the fear that the baby was not growing well and its effect on continuation of breastfeeding; and mother's perception of the role of knowing breastfeeding benefits, having successful experiences with breastfeeding and the effect of domestic responsibilities on the duration of breastfeeding.

\section{Results}

The results of the current study revealed that out of 342 screened mothers 280 were eligible (i.e. their youngest child was $2-3$ years old). Out of the 280 mothers 19 were excluded (4 refused and 15 had had their babies admitted to the NICU for prematurity or congenital malformations) and 27 (9.6\%) had not initiated breastfeeding for their infants. Of the 234 enrolled women 62 (26.5\%) had breastfed for $\geq 6$ months.

The demographic and social characteristics of the study sample are shown in Table 1, which also provides a comparison between mothers who had breastfed for $<6$ months and those who had breastfed for $\geq 6$ months. It shows that mothers who had completed 6 months of breastfeeding initiated their breastfeeding earlier and their infants were weaned at a later age than the mothers who breastfed for $<6$ months and this was a statistically significant difference $(P<0.001)$. Other factors that showed statistical significance were: nationality, level of education, feasibility of breastfeeding at work, timing of receiving breastfeeding information, and self-perceived adequacy of breastmilk.

Table 2 demonstrates factors influencing breastfeeding duration as perceived by the mothers. Among the causes of success only the father's encouragement reached statistical significance $(P=0.019)$. Regarding the reasons for failure only the mother's sickness reached statistical significance $(P=0.046)$.

Factors associated with termination of breastfeeding before 6 months in the regression analysis are summarized in $\mathrm{Ta}$ ble 3. The data show that separate housing, higher maternal age, late initiation of breastfeeding, working without the feasibility of breastfeeding the infant at work, breastfeeding information given after rather than before birth, and maternal and infant sickness were all significant factors influencing early cessation of breastfeeding as reported by mothers. On the other hand, father's encouragement and support to continue breastfeeding was a significant factor that protected against early breastfeeding cessation.

\section{Discussion}

The initiation rate for breastfeeding in the current study was $90.4 \%$, which is close to that reported by Dashti et al. in Kuwait (5) and Xu et al. in China (8). Higher initiation rates of $94 \%, 94.4 \%$ and $98 \%$ were reported among Saudi Arabian (9), Tunisian (11) and Emirati mothers (10) respectively.

Only $26.5 \%$ of the enrolled women in the current study had breastfed for
6 months or more compared with 49.9\% of Arab mothers in Qatar who continued breastfeeding at 1 year (12). Shawky and Abalkhail reported that $40 \%$ of their series of mothers who lived in Jeddah, Saudi Arabia, were breastfeeding at 1 year (9). Reports of breastfeeding practices vary greatly around the world. A Canadian study reported nearly a $100 \%$ initiation rate and $70 \%$ breastfeeding rate at 6 months (13), while another study, from Hong Kong, recorded an initiation rate of only $67 \%$ and by the 6 th week only $26.7 \%$ of mothers were still breastfeeding (14). In western France, an area of low initiation, $25 \%$ of mothers were reported to breastfeed until 6 months (15).

The data of this study highlights that living separately from the rest of family, higher maternal age, later initiation of breastfeeding, no possibility of breastfeeding at work, breastfeeding information given after rather than before birth, maternal and infant sickness as well as absence of father's encouragement were all significant factors influencing early cessation of breastfeeding, as reported by mothers.

The partner's supporting influence and external encouragement for the lactating mother were highlighted in previous studies $(14,16,17)$. Additionally, maternal illness was perceived by the studied mothers as an important cause of failure to breastfeed. Worth mentioning here is that misconceptions regarding breastfeeding are not uncommon. In Kuwait, Ibrahim et al. reported that $66 \%, 60 \%$ and $55 \%$ of female university students thought mothers should temporarily stop breastfeeding if they had a fever, skin rash or sore throat respectively (18).

The current study reported that advanced maternal age was a risk factor for early cessation of breastfeeding. This is contrary to Al-Bustan and Kholi, who demonstrated a positive association between the duration of breastfeeding among Kuwaiti mothers and maternal age as well as parity, and a negative 


\begin{tabular}{|c|c|c|c|c|c|c|c|c|}
\hline \multirow[t]{2}{*}{ Variable } & \multirow{2}{*}{\multicolumn{2}{|c|}{ Total }} & \multicolumn{5}{|c|}{ Duration of breastfeeding } & \multirow[b]{2}{*}{$P$-value } \\
\hline & & & \multicolumn{3}{|c|}{$<6$ months } & \multicolumn{2}{|c|}{$\geq 6$ months } & \\
\hline Maternal age (years) [mean (SD)] & \multicolumn{2}{|c|}{-} & \multicolumn{3}{|c|}{$32.7(9.2)$} & \multicolumn{2}{|c|}{$31.5(5.4)$} & 0.323 \\
\hline Time of starting breastfeeding (hours) [mean (SD)] & \multicolumn{2}{|c|}{-} & \multicolumn{3}{|c|}{$36.1(26.5)$} & \multicolumn{2}{|c|}{$21.7(18.9)$} & $<0.001$ \\
\hline Weaning age (months) [mean (SD)] & \multicolumn{2}{|c|}{-} & \multicolumn{3}{|c|}{$4.53(1.36)$} & \multicolumn{2}{|c|}{$5.16(1.15)$} & 0.001 \\
\hline Nationality (no., \%) & \multicolumn{2}{|c|}{-} & \multicolumn{3}{|c|}{-} & \multicolumn{2}{|c|}{-} & \\
\hline Kuwaiti & 169 & 72.2 & 131 & 76.2 & & 38 & 61.3 & 0020 \\
\hline Non-Kuwaiti & 65 & 27.8 & 41 & 23.8 & & 24 & 38.7 & 0.030 \\
\hline \multicolumn{9}{|l|}{ Education } \\
\hline Primary & 76 & 32.5 & 63 & 36.6 & & 13 & 21.0 & \multirow{3}{*}{0.004} \\
\hline Secondary & 67 & 28.6 & 53 & 30.8 & & 14 & 22.6 & \\
\hline University & 91 & 38.9 & 56 & 32.6 & & 35 & 56.5 & \\
\hline \multicolumn{9}{|l|}{ Residence (no., \%) } \\
\hline With family & 177 & 75.6 & 134 & 77.9 & & 43 & 69.4 & \multirow{2}{*}{0.241} \\
\hline Separate housing & 57 & 24.4 & 38 & 22.1 & & 19 & 30.6 & \\
\hline \multicolumn{9}{|l|}{ Breastfed before (no., \%) } \\
\hline Yes & 170 & 72.6 & 120 & 69.8 & & 50 & 80.6 & \multirow{2}{*}{0.139} \\
\hline No & 64 & 27.4 & 52 & 30.2 & & 12 & 19.4 & \\
\hline \multicolumn{9}{|l|}{ Breastfeeding in the workplace (no., \%) } \\
\hline Not employed & 52 & 22.2 & 33 & 19.2 & & 19 & 30.6 & \\
\hline Can breastfeed at work & 121 & 51.7 & 86 & & 50.0 & 35 & 56.5 & 0.013 \\
\hline Cannot breastfeed at work & 61 & 26.1 & 53 & & 30.8 & 8 & 12.9 & \\
\hline $\begin{array}{l}\text { Timeliness of receiving breastfeeding information } \\
\text { (no., \%) }\end{array}$ & & & & & & & & \\
\hline During pregnancy & 90 & 38.5 & 58 & & 33.7 & 32 & 51.6 & م20 م \\
\hline After birth & 144 & 61.5 & 114 & & 66.3 & 30 & 48.4 & $0.0<0$ \\
\hline $\begin{array}{l}\text { Adequacy of milk production as perceived by moth } \\
\text { (no., \%) }\end{array}$ & & & & & & & & \\
\hline Adequate & 89 & 38.0 & 57 & & 33.1 & 32 & 51.6 & 016 \\
\hline Inadequate & 145 & 62.0 & 115 & & 66.9 & 30 & 48.4 & 0.016 \\
\hline Birth order of child (no., \%) & & & & & & & & \\
\hline $1 s t$ & 40 & 17.1 & 27 & & 15.7 & 13 & 21.0 & \\
\hline 2nd & 62 & 26.5 & 47 & & 27.3 & 15 & 24.2 & \\
\hline $3 \mathrm{rd}$ & 47 & 20.1 & 32 & & 18.6 & 15 & 24.2 & 0.260 \\
\hline 4 th & 34 & 14.5 & 23 & & 13.4 & 11 & 17.7 & \\
\hline$>4$ th & 51 & 21.8 & 43 & & 25.0 & 8 & 12.9 & \\
\hline Source of breastfeeding information (no., \%) & & & & & & & & \\
\hline Doctor & 107 & 45.7 & 73 & & 42.4 & 34 & 54.8 & 0.346 \\
\hline Nurse & 65 & 27.8 & 49 & & 28.5 & 16 & 25.8 & \\
\hline Relatives and friends & 48 & 20.5 & 39 & & 22.7 & 9 & 14.5 & \\
\hline News and media & 14 & 6 & 11 & & 6.4 & 3 & 4.8 & \\
\hline
\end{tabular}

Breastfed refers to any breastfeeding (exclusive and non-exclusive). $S D=$ standard deviation .

association with mother's level of latter one, a finding which needs further education (6). This contradiction might consideration.

be attributed to the inclusion of Arab non-Kuwaiti mothers in the present study which was not the case in the
Similar to the results of the current study, Wang et al. found that the earlier the initiation of breastfeeding, the longer the duration of breastfeeding (14). In addition, the present work suggested that breastfeeding information given before birth can boost rates of breastfeeding, and this agrees with Bouanene et 


\begin{tabular}{|c|c|c|c|c|c|c|c|}
\hline \multirow[t]{3}{*}{ Variable } & \multirow{2}{*}{\multicolumn{2}{|c|}{ Total }} & \multicolumn{4}{|c|}{ Duration of breastfeeding } & \multirow[t]{3}{*}{$P$-value } \\
\hline & & & \multicolumn{2}{|c|}{$<6$ months } & \multicolumn{2}{|c|}{$\geq 6$ months } & \\
\hline & No. & $\%$ & No. & $\%$ & No. & $\%$ & \\
\hline \multicolumn{8}{|l|}{ Previous experience } \\
\hline Not important & 52 & 22.2 & 40 & 23.3 & 12 & 19.4 & \multirow[t]{4}{*}{0.931} \\
\hline Somewhat important & 26 & 11.1 & 19 & 11.0 & 7 & 11.3 & \\
\hline Important & 49 & 20.9 & 35 & 20.3 & 14 & 22.6 & \\
\hline Very important & 107 & 45.7 & 78 & 45.3 & 29 & 46.8 & \\
\hline \multicolumn{8}{|c|}{ Doctor's \& team's encouragement } \\
\hline Not important & 42 & 17.9 & 34 & 19.8 & 8 & 12.9 & \multirow{4}{*}{0.068} \\
\hline Somewhat important & 33 & 14.1 & 20 & 11.6 & 13 & 21.0 & \\
\hline Important & 61 & 26.1 & 50 & 29.1 & 11 & 17.7 & \\
\hline Very important & 98 & 41.9 & 68 & 39.5 & 30 & 48.4 & \\
\hline \multicolumn{8}{|l|}{ Father's encouragement } \\
\hline Not important & 47 & 20.1 & 43 & 25.0 & 4 & 6.5 & \multirow[t]{4}{*}{0.019} \\
\hline Somewhat important & 50 & 21.4 & 34 & 19.8 & 16 & 25.8 & \\
\hline Important & 45 & 19.2 & 32 & 18.6 & 13 & 21.0 & \\
\hline Very important & 92 & 39.3 & 63 & 36.6 & 29 & 46.8 & \\
\hline \multicolumn{8}{|c|}{ Grandmother's encouragement } \\
\hline Not important & 26 & 11.1 & 21 & 12.2 & 5 & 8.1 & \multirow{4}{*}{0.583} \\
\hline Somewhat important & 29 & 12.4 & 21 & 12.2 & 8 & 12.9 & \\
\hline Important & 38 & 16.2 & 25 & 14.5 & 13 & 21.0 & \\
\hline Very important & 141 & 60.3 & 105 & 61.0 & 36 & 58.1 & \\
\hline \multicolumn{8}{|l|}{ Knowledge of benefits } \\
\hline Not important & 3 & 1.3 & 3 & 1.7 & 0 & 0.0 & \multirow[t]{4}{*}{0.248} \\
\hline Somewhat important & 6 & 2.6 & 5 & 2.9 & 1 & 1.6 & \\
\hline Important & 28 & 12.0 & 24 & 14.0 & 4 & 6.5 & \\
\hline Very important & 197 & 84.2 & 140 & 81.4 & 57 & 91.9 & \\
\hline \multicolumn{8}{|l|}{ Mother's sickness } \\
\hline Not important & 117 & 50.0 & 79 & 45.9 & 38 & 61.3 & \multirow[t]{4}{*}{0.046} \\
\hline Somewhat important & 27 & 11.5 & 19 & 11.0 & 8 & 12.9 & \\
\hline Important & 39 & 16.7 & 29 & 16.9 & 10 & 16.1 & \\
\hline Very important & 51 & 21.8 & 45 & 26.2 & 6 & 9.7 & \\
\hline \multicolumn{8}{|l|}{ Baby's sickness } \\
\hline Not important & 100 & 42.7 & 68 & 39.5 & 32 & 51.6 & 0.142 \\
\hline Somewhat important & 42 & 17.9 & 29 & 16.9 & 13 & 21.0 & \\
\hline Important & 36 & 15.4 & 28 & 16.3 & 8 & 12.9 & \\
\hline Very important & 56 & 23.9 & 47 & 27.3 & 9 & 14.5 & \\
\hline Baby not growing well & & & & & & & \\
\hline Not important & 113 & 48.3 & 81 & 47.1 & 32 & 51.6 & \\
\hline Somewhat important & 25 & 10.7 & 14 & 8.1 & 11 & 17.7 & 0.064 \\
\hline Important & 26 & 11.1 & 19 & 11.0 & 7 & 11.3 & \\
\hline Very important & 70 & 29.9 & 58 & 33.7 & 12 & 19.4 & \\
\hline $\begin{array}{l}\text { Effect of domestic respon } \\
\text { mother's ability to breast }\end{array}$ & & & & & & & \\
\hline Not important & 141 & 60.3 & 109 & 63.4 & 32 & 51.6 & \\
\hline Somewhat important & 21 & 9.0 & 11 & 6.4 & 10 & 16.1 & 0.106 \\
\hline Important & 55 & 23.5 & 39 & 22.7 & 16 & 25.8 & \\
\hline Very important & 17 & 7.3 & 13 & 7.6 & 4 & 6.5 & \\
\hline
\end{tabular}




\begin{tabular}{|c|c|c|}
\hline Variable & Hazard ratio & $95 \% \mathrm{Cl}$ \\
\hline \multicolumn{3}{|l|}{ Residence } \\
\hline With family & $1.00^{\mathrm{a}}$ & - \\
\hline Separate housing & 1.77 & $1.20-2.59$ \\
\hline Age (years & 0.98 & $0.96-1.00$ \\
\hline Time of starting breastfeeding (hours & 1.01 & $1.00-1.01$ \\
\hline \multicolumn{3}{|l|}{ Breastfeeding in the workplace } \\
\hline Not employed & $1.00^{\mathrm{a}}$ & - \\
\hline Can breastfeed at work & 1.17 & $0.75-1.83$ \\
\hline Cannot breastfeed at work & 1.71 & $1.07-2.74$ \\
\hline \multicolumn{3}{|c|}{ Timeliness of receiving breastfeeding information } \\
\hline After birth & $1.00^{\mathrm{a}}$ & - \\
\hline During pregnancy & 0.60 & $0.43-0.84$ \\
\hline \multicolumn{3}{|l|}{ Mother's sickness } \\
\hline Not important & $1.00^{\mathrm{a}}$ & - \\
\hline Somewhat important & 1.03 & $0.60-1.76$ \\
\hline Important & 1.07 & $0.67-1.70$ \\
\hline Very important & 2.61 & $1.74-3.91$ \\
\hline \multicolumn{3}{|l|}{ Baby's sickness } \\
\hline Not important & $1.00^{\mathrm{a}}$ & - \\
\hline Somewhat important & 1.09 & $0.68-1.74$ \\
\hline Important & 1.47 & $0.89-2.43$ \\
\hline Very important & 1.78 & $1.19-2.66$ \\
\hline \multicolumn{3}{|l|}{ Father's encouragement } \\
\hline Not important & $1.00^{\mathrm{a}}$ & - \\
\hline Somewhat important & 0.27 & $0.16-0.46$ \\
\hline Important & 0.30 & $0.18-0.50$ \\
\hline Very important & 0.33 & $0.21-0.52$ \\
\hline
\end{tabular}

${ }^{a}$ Reference group; $\mathrm{Cl}=$ confidence interval.

al., who emphasized the importance of giving breastfeeding information before rather than after birth (11), and Wang et al., who highlighted the importance of mothers' intention to breastfeed in the success of the practice (14).

Being employed without having the feasibility to breastfeed at work was reported by our sample of mothers as an important determinant for cessation of breastfeeding. Bonet et al. reported that the sooner the mothers returned to work, the less likely they were breastfed their babies at 4 months of infant's age, independently of full-time or part-time employment (19). The authors further added that in a society where breastfeeding is not the norm, women may have difficulties combining work and breastfeeding, a situation which should not pose a problem in the Arab world, where breastfeeding is the norm.

Legislation in most Arab countries is derived from Islamic sharia law based on the Holy Quran and the Hadiths. The Quran says that the mothers shall give suck to their offspring for 2 complete years (20), which might give Arab mothers an advantage over mothers in other cultures. Nevertheless, the rate of mothers' breastfeeding for $\geq 6$ months recorded in the current study are still far below WHO recommendations.

The current work had its own limitations. The mothers were enrolled from one hospital, and only the clinics attended by the principle researcher were utilized for sample collection, which could have contributed to the small sample size, although this was done to minimize interviewer bias. Possible recall bias by the mothers was another limitation. An important limitation was that our definition of breastfeeding covered any type breastfeeding; future research enrolling a large number of exclusively breastfed infants might show significant associations specific to this category. Nonetheless, the current work addressed the low rate of breastfeeding in this part of the world and highlighted important factors that can be specifically modified to enhance the practice.

In conclusion, breastfeeding practice in Kuwait showed a good rate of initiation yet a poor rate of continuation. The common causes for failure to proceed in breastfeeding were separate family housing, higher maternal age, late initiation of breastfeeding, being employed without having the feasibility to breastfeed at work, breastfeeding information given after rather than before birth, and maternal and infant sickness. Preventive strategies are needed for boosting breastfeeding in Kuwait with special emphasis on these points with the aim of full implementation of the WHO global public health recommendations for exclusive breastfeeding.

\section{References}

1. Global Strategy for Infant and Young Child Feeding. Geneva: World Health Organization; 2003 (http://www.who.int/nutrition/publications/gs_infant_feeding_text_eng.pdf, accessed 19 April 2014).
2. Morales E, García-Esteban R, Guxens M, Guerra S, Mendez M, Moltó-Puigmartí C, et al. Effects of prolonged breastfeeding and colostrum fatty acids on allergic manifestations and infections in infancy. Clin Exp Allergy. 2012 Jun;42:918-28. PMID:22909163 
3. Kramer MS et al. Promotion of Breastfeeding Intervention Trial (PROBIT): a randomized trial in the Republic of Belarus. JAMA. 2001 Jan 24-31;285(4):413-20. PMID:11242425

4. Nwaru BI, Takkinen HM, Niemelä O, Kaila M, Erkkola M, Ahonen $\mathrm{S}$, et al. Timing of infant feeding in relation to childhood asthma and allergic diseases. J Allergy Clin Immunol. 2013 Jan;131(1):78-86. PMID:23182171

5. Dashti M, Scott JA, Edwards CA, Al-Sughayer M. Determinants of breastfeeding initiation among mothers in Kuwait. Int Breastfeed J. 2010;5:7. PMID:20667112

6. Al Bustan M, Kohli BR. Socio-economic and demographic factors influencing breast-feeding among Kuwaiti women. Genus. 1988 Jan-Jun;44(1-2):265-78. PMID:12281668

7. Infant Feeding Practices Study II. Project FIRST infant month 2 questionnaire. Global opinion panels [Internet]. Atlanta (GA): Centers for Disease Control and Prevention; 2007 (http:// www.cdc.gov/ifps/pdfs/IFPS_II/month2/Month2GOP.pdf, accessed 19 April 2014).

8. Xu F, Binns C, Yu P, Bai Y. Determinants of breastfeeding initiation in Xinjiang, PR China, 2003-2004. Acta Paediatr. 2007 Feb;96(2):257-60. PMID:17429916

9. Shawky S, Abalkhail BA. Maternal factors associated with the duration of breast feeding in Jeddah, Saudi Arabia. Paediatr Perinat Epidemiol. 2003 Jan;17(1):91-6. PMID:12562476

10. Radwan H. Patterns and determinants of breastfeeding and complementary feeding practices of Emirati Mothers in the United Arab Emirates. BMC Public Health. 2013, 13:171 doi:10.1186/1471-2458-13-171.

11. Bouanene I, EIMhamdi S, Sriha A, Bouslah A, Soltani M. Connaissances et pratiques des femmes de la région de Monastir (Tunisie) concernant I'allaitement maternel. [Knowledge and practices of women in Monastir, Tunisia regarding breastfeeding]. East Mediterr Health J. 2010 Aug;16(8):879-85. PMID:21473131

12. Al-Kohji S, Said HA, Selim NA. Breastfeeding practice and determinants among Arab mothers in Qatar. Saudi Med J. 2012 Apr;33(4):436-43. PMID:22485241
13. Kehler HL, Chaput KH, Tough SC. Risk factors for cessation of breastfeeding prior to six months postpartum among a community sample of women in Calgary, Alberta. Can J Public Health. 2009 Sep-Oct;100(5):376-80. PMID:19994742

14. Wang W, Lau Y, Chow A, Chan KS. Breast-feeding intention, initiation and duration among Hong Kong Chinese women: a prospective longitudinal study. Midwifery. 2013 Jul 26; doi:10.1016/j.midw.2013.07.015. PMID:23962638

15. Branger B, Dinot-Mariau L, Lemoine N, Godon N, Merot E, Brehu S, et al. Durée d'allaitement maternel et facteurs de risques d'arrêt d'allaitement : évaluation dans 15 maternités du Réseau de santé en périnatalité des Pays de la Loire. [Duration of breastfeeding from 15 maternity wards of the perinatal network in the Pays de la Loire area]. Arch Pediatr. 2012 Nov;19(11):1164-76. PMID:23031316

16. Hernández PT, Callahan S. Attributions of breastfeeding determinants in a French population. Birth. 2008 Dec;35(4):303-12. PMID:19036043

17. Morrison L, Reza A, Cardines K, Foutch-Chew K, Severance C. Determinants of infant-feeding choice among young women in Hilo, Hawaii. Health Care Women Int. 2008 Sep;29(8):80725. PMID:18726793

18. Ebrahim B, Al-Enezi H, Al-Turki M, Al-Turki A, Al-Rabah F, Hammoud MS, et al. Knowledge, misconceptions, and future intentions towards breastfeeding among female university students in Kuwait. J Hum Lact. 2011 Nov;27(4):358-66. PMID:21813801

19. Bonet M, Marchand L, Kaminski M, Fohran A, Betoko A, Charles MA, et al. Breastfeeding duration, social and occupational characteristics of mothers in the French "EDEN motherchild" cohort. Matern Child Health J. 2013 May;17(4):714-22. PMID:22729659

20. Al-Jassir M, Moizuddin SK, Al-Bashir B. A review of some statistics on breastfeeding in Saudi Arabia. Nutr Health. 2003;17(2):123-30. PMID:14653507 